Check for updates

Cite this: Chem. Sci., 2019, 10, 5749

๑ All publication charges for this article have been paid for by the Royal Society of Chemistry

Received 10th September 2018 Accepted 21st April 2019

DOI: $10.1039 / \mathrm{c} 8 \mathrm{sc} 04023 \mathrm{k}$

rsc.li/chemical-science

\section{Finding intersections between electronic excited state potential energy surfaces with simultaneous ultrafast X-ray scattering and spectroscopy ${ }_{\dagger}$}

Kasper S. Kjær, (D) *abc Tim B. Van Driel, ${ }^{d}$ Tobias C. B. Harlang, ${ }^{\text {bc }}$ Kristjan Kunnus, ${ }^{a}$

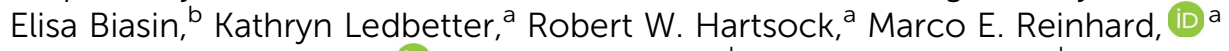
Sergey Koroidov, ${ }^{a}$ Lin Li, (D) a Mads G. Laursen, ${ }^{\text {b }}$ Frederik B. Hansen, ${ }^{\text {b }}$ Peter Vester, ${ }^{\text {b }}$ Morten Christensen, (D) ${ }^{\mathrm{b}}$ Kristoffer Haldrup, ${ }^{\mathrm{b}}$ Martin M. Nielsen, (DD ${ }^{\mathrm{b}}$

Asmus O. Dohn, (D) e Mátyás I. Pápai, ef Klaus B. Møller, (D) e Pavel Chabera, (D) ${ }^{c}$ Yizhu Liu, ${ }^{\mathrm{cg}}$ Hideyuki Tatsuno, ${ }^{\mathrm{C}}$ Cornelia Timm, ${ }^{\mathrm{C}}$ Martin Jarenmark, ${ }^{\mathrm{h}}$ Jens Uhlig, ${ }^{\mathrm{c}}$ Villy Sundstöm, ${ }^{c}$ Kenneth Wärnmark, ${ }^{g}$ Petter Persson, (D) i Zoltán Németh, (D) ${ }^{f}$ Dorottya Sárosiné Szemes, (DD ${ }^{f}$ Éva Bajnóczi, ${ }^{f}$ György Vankó, (DD ${ }^{f}$ Roberto AlonsoMori, ${ }^{d}$ James M. Glownia, ${ }^{d}$ Silke Nelson, ${ }^{d}$ Marcin Sikorski, ${ }^{d}$ Dimosthenis Sokaras, ${ }^{j}$ Sophie E. Canton, (D) ${ }^{\mathrm{kl}}$ Henrik T. Lemke ${ }^{\mathrm{dm}}$ and Kelly J. Gaffney (D) *aj

\section{Introduction}

Potential energy surfaces dictate molecular and chemical dynamics. For chemical reactions on the electronic ground state potential, transition state theory usually provides a strong foundation for understanding chemical reactivity because intrawell equilibration precedes chemical reaction and reactive trajectories proceed along adiabatic trajectories through the
${ }^{a}$ PULSE Institute, SLAC National Accelerator Laboratory, Stanford University, Menlo Park, California 94025, USA.E-mail: kaspersk@gmail.com; kgaffney@slac.stanford. $e d u$

${ }^{b}$ Department of Physics, Technical University of Denmark, DK-2800, Lyngby, Denmark

'Department of Chemical Physics, Lund University, P.O. Box 124, 22100 Lund, Sweden

${ }^{d}$ LCLS, SLAC National Accelerator Laboratory, Menlo Park, California 94025, USA ${ }^{e}$ Science Institute, University of Iceland, 107 Reykjavik, Iceland

${ }^{f}$ Wigner Research Centre for Physics, Hungarian Academy of Sciences, P.O. Box 49, H-1525 Budapest, Hungary

${ }^{g}$ Centre for Analysis and Synthesis, Department of Chemistry, Lund University, P.O. Box 124, 22100 Lund, Sweden
${ }^{h}$ Department of Geology, Department of Chemistry, Lund University, 22362 Lund, Sweden

${ }^{i}$ Theoretical Chemistry Division, Department of Chemistry, Lund University, P.O. Box 124, 22100 Lund, Sweden

${ }^{i}$ SSRL, SLAC National Accelerator Laboratory, Menlo Park, California 94025, USA ${ }^{k}$ ELI-ALPS, ELI-HU Non-Profit Ltd., Dugonics ter 13, Szeged 6720, Hungary ${ }^{l}$ FS-ATTO, Deutsches Elektronen-Synchrotron (DESY), Notkestrasse 85, D-22607 Hamburg, Germany

${ }^{m}$ SwissFEL, Paul Scherrer Institut, Villigen PSI 5232, Switzerland

$\dagger$ Electronic supplementary information (ESI) available. See DOI: $10.1039 / \mathrm{c} 8 \mathrm{sc} 04023 \mathrm{k}$ 
transition state with minimal damping. ${ }^{\mathbf{1 - 3}}$ Chemical reactions on electronic excited state potentials differ fundamentally from those on the electronic ground state potential. Reactions can proceed faster than excited state equilibration and reaction dynamics often depend critically on the location of intersections between potential energy surfaces (PES) where nonadiabatic effects govern the transition probabilities between distinct electronic state potential energy surfaces. ${ }^{4-7}$ These points of intersection can be seen as the analog of the transition state for electronic excited state chemical reactions and understanding the reaction mechanism of electronic excited states entails identifying the location of these intersections.

Robustly identifying the location of intersections and weakly avoided crossings that control the relaxation dynamics of electronic excited states has long been a goal and challenge of ultrafast photochemical studies. ${ }^{7-9}$ Landmark studies by Zewail and co-workers on the photodissociation of $\mathrm{NaI}^{8,10}$ and Fleming and co-workers on the photodissociation of $\mathrm{I}_{2}$ in solution ${ }^{\mathbf{1 1}}$ demonstrated the ability of femtosecond spectroscopy in the visible and UV to identify the diatomic bond length where population transfer between distinct electronic states occurred. The extension of these methods to more complex photochemical reaction mechanisms and molecular systems has been widely successful, but the extraction of quantitative information about excited state reactive trajectories has proven much more challenging. Addressing this challenge requires the development of more direct and differentiated probes of electronic and nuclear dynamics. With the advent of ultrafast X-ray laser sources, ${ }^{12}$ for which the time-resolution of solution-state experiments was recently pushed below 30 femtoseconds, ${ }^{13}$ powerful X-ray scattering and spectroscopy tools for characterizing steady state nuclear and electronic structure can now be extended to measure ultrafast electronic transitions and nuclear dynamics. ${ }^{13-22}$

This work uses simultaneous Fe $3 \mathrm{p}-1 \mathrm{~s}(\mathrm{~K} \beta)$ X-ray emission spectroscopy (XES) and X-ray diffuse scattering (XDS) measurements (Fig. 1C), first demonstrated by Canton et al. ${ }^{20}$ to quantify the electronic excited state trajectories of $\left[\mathrm{Fe}(\mathrm{bpy})_{3}\right]^{2+}$. For 3d transition metal centered molecular systems, timeresolved $\mathrm{K} \beta$ XES accesses the electronic spin moment on the metal center ${ }^{1,23,24}$ and time-resolved XDS accesses the dominant changes in intramolecular nuclear structure around the metal center, ${ }^{2,3,25,26}$ respectively. Fits of the XES and XDS data enable explicit quantification of electronic and structural degrees of freedom. Fitting the dynamics of these quantified parameters makes it possible to retrieve unambiguous mechanistic information on the ensemble of electronic excited state trajectories. By optimizing a model-description for the excited state relaxation on multiple potential energy surfaces, against the quantified electronic and structural parameters, it becomes possible to identify the dominant trajectory followed during electronic excited state relaxation and the relevant loci of intersections between electronic states from the experimental results. If the excited state cascade transitions between two surfaces more than once with different loci of intersection, these start revealing the seam of intersection in multidimensional reaction coordinate space.
To showcase this methodology, we have characterized the ensemble of electronic excited state trajectories and quantified key parameters for the excited state potential energy surfaces governing the photo-induced spin crossover process in the prototypical $\mathrm{Fe}(\mathrm{II})$ low-spin complex $\left[\mathrm{Fe}\left(2,2^{\prime} \text {-bipyridine }\right)_{3}\right]^{2+}$ $\left(\left[\mathrm{Fe}(\mathrm{bpy})_{3}\right]^{2+}\right)$. Photo-induced spin crossover in $\left[\mathrm{Fe}(\mathrm{bpy})_{3}\right]^{2+}$ provides a system well-suited to demonstrating the power of this experimental approach. Photo-excitation of the singlet ground state of $\left[\mathrm{Fe}(\mathrm{bpy})_{3}\right]^{2+}$ generates a singlet metal-to-ligand charge-transfer ( $\left.{ }^{1} \mathrm{MLCT}\right)$ that undergoes intersystem crossing to the ${ }^{3}$ MLCT state in $20 \mathrm{fs}^{27}$ This ${ }^{3}$ MLCT then relaxes to a high spin metal centered quintet state $\left({ }^{5} \mathrm{MC}\right)$ within 200 fs (ref. 4, 14, 19 and 28-30) and coherently excites the Fe-N symmetric stretching mode of the ${ }^{5} \mathrm{MC}$ state. ${ }^{11,13}$ What remains under dispute is the mechanism for transforming the MLCT excitation into the high spin ${ }^{5} \mathrm{MC}$ state, as demonstrated by the different, and incompatible, models used in the interpretation of three recent experimental investigations..$^{13,15,31}$ Theoretical calculations have assisted in assessing the viability of alternative relaxation mechanisms. ${ }^{32-36}$ Initial studies concluded that a sequential relaxation mechanism involving a ${ }^{3} \mathrm{MC}$ should dominate, ${ }^{35}$ but more recent studies indicate direct ${ }^{3}$ MLCT relaxation to the ${ }^{5} \mathrm{MC}$ excited state may compete with the sequential mechanism. ${ }^{32,33}$ The sensitivity of the second-order spin-orbit coupling magnitude to the specific geometry of the $\left[\mathrm{Fe}(\mathrm{bpy})_{3}\right]^{2+}$ in the ${ }^{3} \mathrm{MLCT}$ excited state found by Sousa and coworkers $^{32,33}$ demonstrates the need for direct dynamics simulations to theoretically determine the relative importance of the direct and sequential mechanisms. Experimentally, we have chosen to determine the relative importance of these alternative mechanisms for photo-induced spin crossover by combining XES and XDS measurements. From this study we conclude the sequential mechanism dominates. More importantly, we demonstrate the ability of simultaneous XES and XDS measurements to map reactive trajectories in transition metal complexes and identify the $\mathrm{Fe}-\mathrm{N}$ bond lengths that form a seam of crossings between the ${ }^{3} \mathrm{MC}$ and ${ }^{5} \mathrm{MC}$ states.

\section{Results and discussion}

For the combined X-ray Emission Spectroscopy (XES) and X-ray Diffuse Scattering (XDS) experiment, we implemented parallel detection of the XES and XDS signal at the X-ray pump-probe (XPP) end station of the Linear Coherent Light Source (LCLS). A schematic of the setup is presented in Fig. 1C. The parallel implementation of XES and XDS ensures that the experimental parameters such as time-zero $\left(t_{0}\right)$, instrument response function $\left(\sigma_{\text {IRF }}\right)$ and excitation fraction $(\alpha)$ are identical for the data measured for the two techniques. Having identical experimental parameters facilitate parallel modeling of the data from the two techniques, allowing us to include both electronic configuration and nuclear structure in our model of the excited state relaxation. Additionally, we have separated the XDS signal into isotropic and anisotropic difference scattering components. $^{37}$ Due to the quasi-octahedral symmetry of the $\left[\mathrm{Fe}(\mathrm{bpy})_{3}\right]^{2+}$ system, we expect neither the solute structural dynamics nor the solvation dynamics associated with photo- 

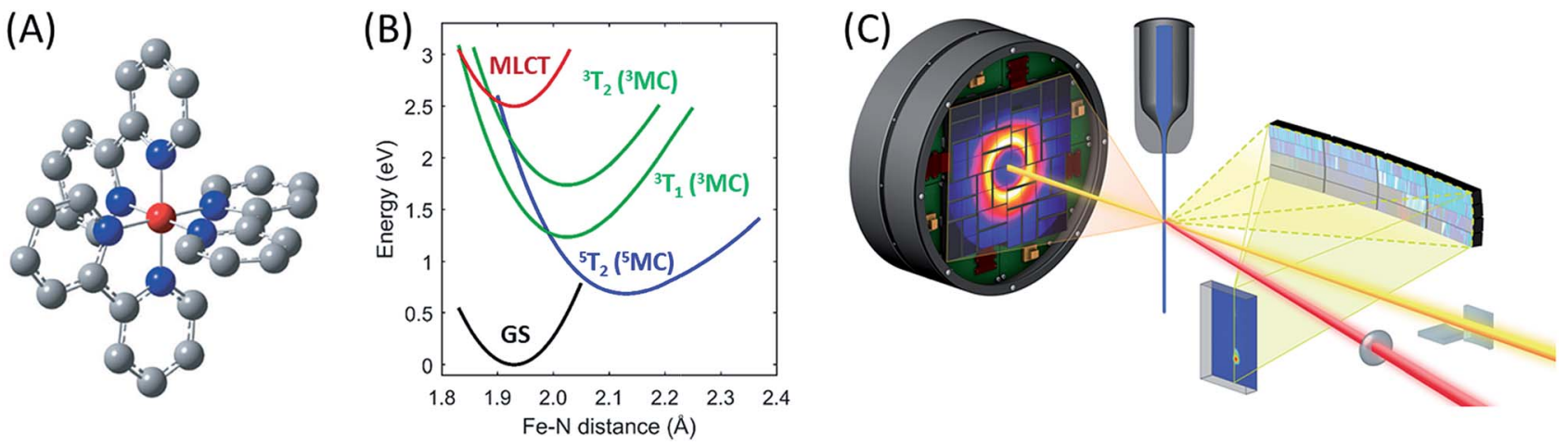

Fig. 1 The $\left[\mathrm{Fe}(\mathrm{bpy})_{3}\right]^{2+}$ complex under investigation, $\mathrm{Fe}$ (red), N (blue), C (grey), $\mathrm{H}$ not shown (A), its most important ground and excited state potential energies as a function of Fe-N bond length (B) from Sousa et al. ${ }^{35}$ and the experimental setup (C).

induced spin crossover to exhibit anisotropy with respect to the polarization of the excitation pulses. Indeed, we show that the anisotropic XDS signal can be described solely from the nuclearcoordinate impulse-response of the water solvent molecules in the pump laser field. This solvent impulse-response allows us to explicitly determine the time-zero of the experiment and the instrument response function ${ }^{16}$ as described in the ESI. $\dagger$

In the present experiment, a $75 \mathrm{mM}$ aqueous solution of $\left[\mathrm{Fe}(\mathrm{bpy})_{3}\right]^{2+}$ was pumped through a $30 \mu \mathrm{m}$ diameter nozzle producing a cylindrical liquid jet. The sample was excited with $400 \mathrm{~nm}$ optical laser pulses with a $120 \mu \mathrm{m}$ focal diameter (FWHM), and $12.5 \mu \mathrm{J}$ per pulse energy, delivering a pulse fluence of $85 \mathrm{~mJ} \mathrm{~cm}^{-2}$, predominantly within the linear absorption regime of $\left[\mathrm{Fe}(\mathrm{bpy})_{3}\right]^{2+},{ }^{13,38,39}$ and before the onset of multiphoton absorption of the water solvent, as discussed in ESI Note $10 . \dagger$ The sample was probed by $8.5 \mathrm{keV} \mathrm{X-ray} \mathrm{laser} \mathrm{pulses} \mathrm{of} 10$ $\mu \mathrm{m}$ focal diameter. The Fe $3 \mathrm{p}-1 \mathrm{~s}$ (K $\beta$ ) fluorescence XES signal was detected on a 140k Cornell-SLAC Pixel Array Detector (CSPAD) located above the liquid jet using four dispersive Ge(620) crystal analyzers with a central Bragg angle of 79.1 degrees. The diffuse X-ray scattering was recorded on an area detector located behind the sample. The relative timing between optical laser pump and X-ray laser probe pulses was measured for each pump-probe event through optical detection of X-ray generated carriers in a $\mathrm{Si}_{3} \mathrm{~N}_{4}$ thin film located before the liquid jet. X-ray and optical laser pulse lengths were estimated as $30 \mathrm{fs}$ and $45 \mathrm{fs}$, respectively. ${ }^{40}$

The full 2D images of the XES and XDS detectors were read out for each pump-probe event, these images were normalized and corrected, ${ }^{41}$ and an unpumped reference signal was subtracted..$^{25}$ The XDS difference images were decomposed into isotropic and anisotropic difference scattering curves $\left(\mathrm{S}_{0}\right.$ and $\left.\mathrm{S}_{2}\right)$ according to the zeroth and second order Legendre polynomials as described by Biasin et al. ${ }^{37}$ We used the anisotropic $\mathrm{S}_{2}$ XDS signal to identify time zero and the instrument response function, $t_{0}=0 \pm 10 \mathrm{fs}$ and $\sigma_{\mathrm{IRF}}=27 \pm 7 \mathrm{fs}$ rms or $64 \pm 7 \mathrm{fs}$ FWHM, as described in the ESI. $\dagger$ The isotropic XDS signal $\left(\mathrm{S}_{0}\right)$ was used for determining the structural dynamics.

The difference images of each pump/probe event were then sorted into $\sim 430$ individual $2.5 \mathrm{fs}$ time bins according to their time stamp and averaged. The resultant XES and isotropic XDS signals are shown in Fig. 2A and B, respectively. All XDS data are scaled to one liquid unit cell, ${ }^{25}$ and all XES spectra are scaled such that the integral of the $\mathrm{K} \beta$ emission line is $1 \mathrm{keV}$.

\section{XES}

We describe the XES signal of excited states of $\left[\mathrm{Fe}(\mathrm{bpy})_{3}\right]^{2+}$ using ground state spectra of Fe-centered complexes with identical charge- and spin-state multiplicities. By selecting reference compounds with ligand bond covalency similar to $\left[\mathrm{Fe}(\mathrm{bpy})_{3}\right]^{2+}$, good agreement between the reference spectra and the measured data is expected. ${ }^{15,24,42}$ The relevant reference difference spectra of the excited states are constructed by subtracting the ground state spectrum of $\left[\mathrm{Fe}(\mathrm{bpy})_{3}\right]^{2+}$ from these reference signals. The reference difference spectra of the MLCT, ${ }^{3} \mathrm{MC}$, and ${ }^{5} \mathrm{MC}$ states are shown in Fig. 3B.

We used the XES signal to quantify the excitation fraction, and subsequently, to determine the evolution of the excited electronic states. The excitation fraction, defined as the total fraction of $\left[\mathrm{Fe}(\mathrm{bpy})_{3}\right]^{2+}$ in any of the excited states $(\alpha(t)=$ $\left.\alpha(t)_{\mathrm{MLCT}}+\alpha(t)_{{ }^{3} \mathrm{MC}}+\alpha(t)_{{ } \mathrm{MC}}\right)$ was determined by scaling the ${ }^{5} \mathrm{MC}$ reference difference signal to the difference data recorded at times $>800 \mathrm{fs}$, assuming complete conversion to the quintet state $\left(\alpha(800 \mathrm{fs})=\alpha(800 \mathrm{fs})^{5} \mathrm{MC}\right)$, providing a total excitation fraction of $42 \%$. Combining $t_{0}$ and $\sigma_{\mathrm{IRF}}$ with the known unitary quantum yield for ${ }^{5} \mathrm{MC}$ state formation, the excitation fraction can be determined as a function of time. We used the transient excitation fraction extracted from XES analysis to constrain the analysis of the isotropic XDS data.

The difference XES signal at each time delay, $\Delta I(E, t)$, was then fitted by a sum of the MLCT, ${ }^{3} \mathrm{MC}$, and ${ }^{5} \mathrm{MC}$ reference difference spectra $\left(\Delta I(E)_{\mathrm{MLCT}}, \Delta I(E)_{{ }^{3} \mathrm{MC}}, \Delta I(E)_{{ }^{\mathrm{MC}}}\right.$, respectively) such that,

$$
\begin{aligned}
\Delta I(E, t)=\alpha(t)_{\mathrm{MLCT}} \Delta I(E)_{\mathrm{MLCT}}+\alpha(t)^{3} \mathrm{MC} \Delta I(E)^{3} \mathrm{MC} & \\
& +\alpha(t)^{{ } \mathrm{MC}} \Delta I(E)^{\mathrm{s}} \mathrm{MC}
\end{aligned}
$$

where the fraction of excited states were fitted while constrained to the known total excitation fraction.

Finally, we imposed the constraint that the MLCT state population decays exponentially, as seen clearly in the studies of Lemke et al., Auböck et al., and all previous ultrafast 
(A)

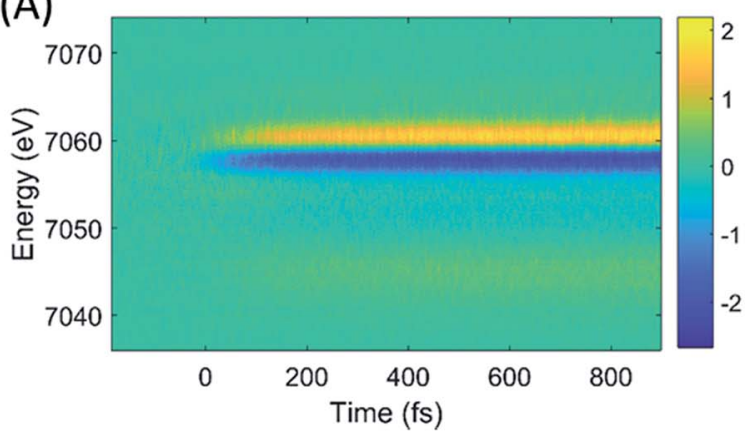

(B)

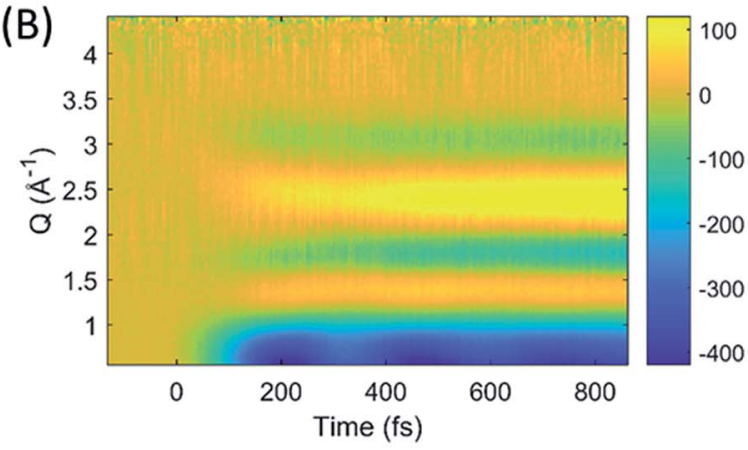

Fig. 2 The time-resolved difference XES (A) and XDS (B) signals generated by photoexcitation of $\left[\mathrm{Fe}(\mathrm{bpy})_{3}\right]^{2+}$ at $400 \mathrm{~nm}$.

studies. ${ }^{\mathbf{1 3 , 1 5 , 2 7 - 2 9 , 3 1}}$ By applying this exponential decay constraint to the MLCT decay, the MLCT and ${ }^{3} \mathrm{MC}$ state populations are robustly differentiated, as described in the ESI. $\dagger$ Convolution with the known time-zero and IRF results in the following expression for the transient population of MLCT states:

$$
\alpha(t)_{\text {MLCT }}=\alpha \int_{-\infty}^{\infty} \mathrm{e}^{\frac{-(t-\tau)}{\tau_{\text {MLCT }}}} \cdot \mathrm{e}^{\frac{-\left(t-t_{0}\right)^{2}}{2 \sigma_{\text {IRF }}}} \mathrm{d} \tau
$$

The MLCT lifetime $\left(\tau_{\text {MLCT }}\right)$ returning the lowest residual in the excited state extraction is $110 \pm 11 \mathrm{fs}$, similar to the $120 \pm 10$ fs lifetime extracted from the most recent XANES study. ${ }^{13}$ Fig. 3A shows the fit of the full model to the data at selected time delays. The reference difference spectra are shown in Fig. 3B, and the full fit of the three components to the difference signal recorded at $150 \mathrm{fs}$ time delay is shown in Fig. 3C. The excited state distribution for all recorded time delays is presented in Fig. 5 (colored circles).
(A)

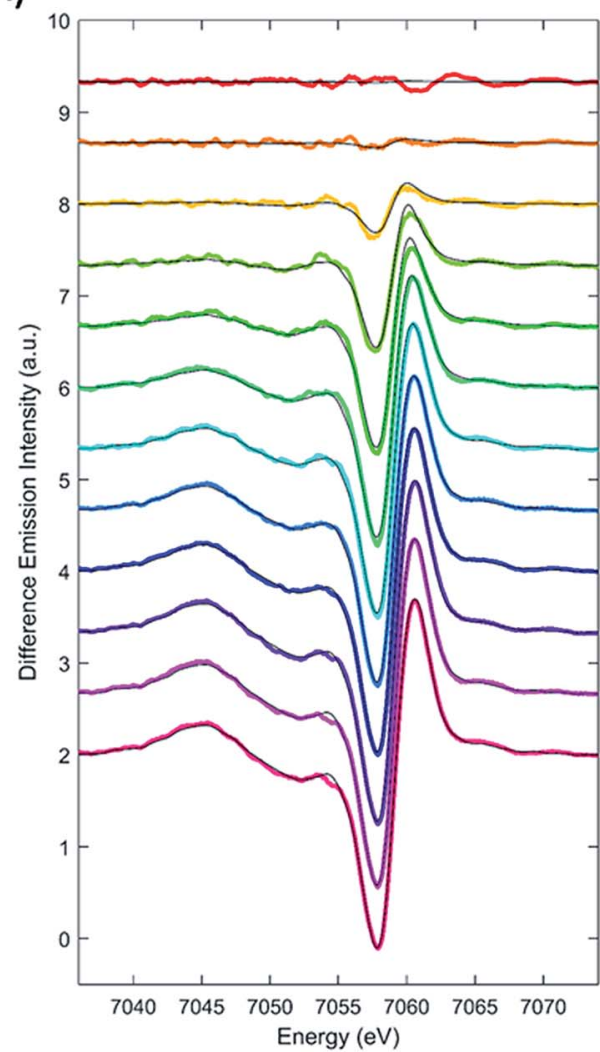

(B)
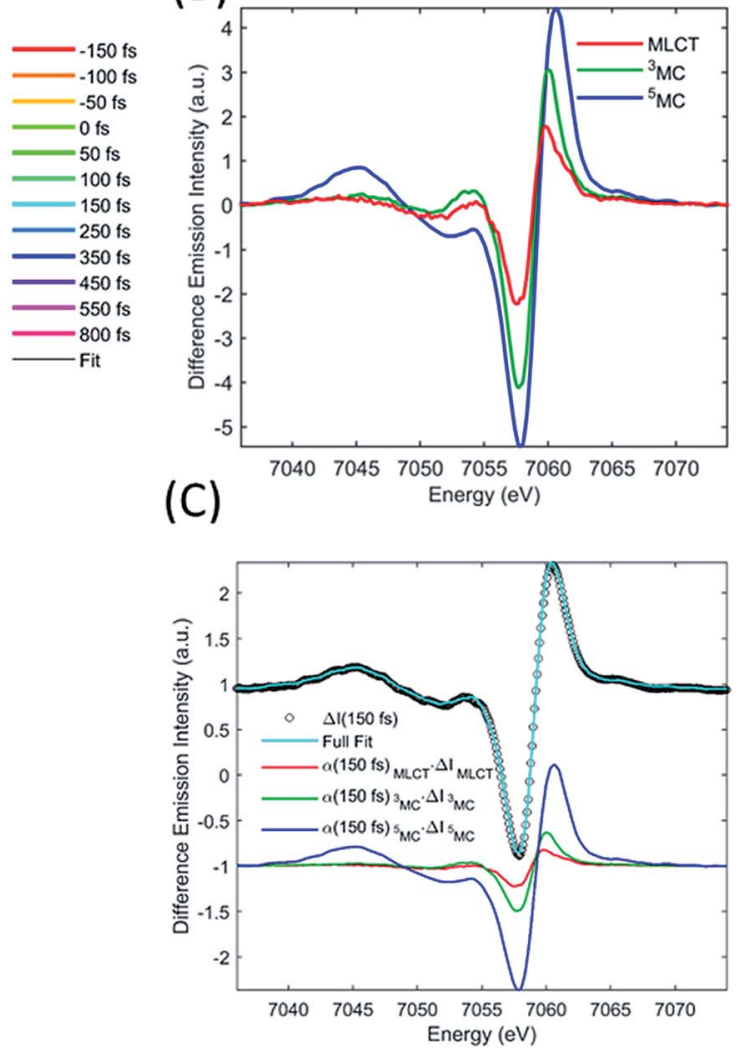

Fig. 3 Fit of the transient XES signal by model described in text. XES data recorded at selected time delays (colored curves) and model fit (grey curves) (A). Reference difference curves used to fit the data (B). The model spectra are constructed from ground-state iron complexes with different spin moments; singlet: $\left[\mathrm{Fe}(\mathrm{bpy})_{3}\right]^{2+}$, doublet: $\left[\mathrm{Fe}(\mathrm{bpy})_{3}\right]^{3+}$, triplet: iron(II)phthalocyanine, quartet: iron(III) phthalocyanine, and quintet $\left[\mathrm{Fe}(\text { phenanthroline })_{2}(\mathrm{NCS})_{2}\right]$. Data, fit and fit components for the $150 \mathrm{fs}$ time-delay data (C). 


\section{XDS}

The XDS signal $\Delta S(Q, t)$, arises from all structural dynamics induced by the excitation event. In the standard analysis formalism, ${ }^{25,43}$ the isotropic XDS signal is modeled as a sum of three contributions arising from changes in solute structure, changes in solvation cage structure, and changes in the bulk solvent structure:

$$
\begin{array}{r}
\Delta S(Q, t)=\Delta S_{\text {solute }}(Q, t)+\Delta S_{\text {solvation cage }}(Q, t) \\
+\Delta S_{\text {bulk solvent }}(Q, t)
\end{array}
$$

Each of these contributions can be further separated into specific molecular structural distortions and solvation processes. The XDS signal is analyzed by simulating the contribution from each of these contributions and comparing the sum of these to experiment.

As discussed by Haldrup et al., ${ }^{\mathbf{1 9 4 4}}$ the XDS signal from $\left[\mathrm{Fe}(\mathrm{bpy})_{3}\right]^{2+}$ on sub-nanosecond time scales can be described using three main components. (1) A single solute component for the structural dynamics quantifying a symmetric expansion of the $\mathrm{Fe}-\mathrm{N}$ bond lengths $\Delta S_{d(\mathrm{Fe}-\mathrm{N})}(Q, t)$. (2) A solvation cage component describing the change in the solute-solvent cross correlation induced by the structural difference between lowand high-spin $\left[\mathrm{Fe}(\mathrm{bpy})_{3}\right]^{2+} \Delta S_{\text {cage }}(Q)$ multiplied by a timedependent scaling factor, $\beta(t)$, that represents the time required for the solvent cage to equilibrate to $\left[\mathrm{Fe}(\mathrm{bpy})_{3}\right]^{2+}$ in the ${ }^{5} \mathrm{MC}$ excited state. (3) A component from a transient increase in the thermal energy of the solvent $\Delta T(t)$ following transfer of excess excitation energy from $\left[\mathrm{Fe}(\mathrm{bpy})_{3}\right]^{2+}$, modelled by the difference scattering signal from a bulk solvent temperature increase $\Delta S_{T}(Q)$. In this previous work on $\left[\mathrm{Fe}(\mathrm{bpy})_{3}\right]^{2+}$ it was found that the fit quality was improved if a transient density increase $\Delta \rho(t)$, modeled by the difference signal of increased bulk solvent density $\Delta S_{\rho}(Q)$, was included as well. Density changes normally arise from thermal expansion on 10-100 ns time scales, but for $\left[\mathrm{Fe}(\mathrm{bpy})_{3}\right]^{2+}$ a fast increase in solvent density has previously been observed ${ }^{\mathbf{1 9}}$ and assigned to an expulsion of water molecules from the solvent cage into the bulk solvent as predicted from simulations. ${ }^{45}$ However, recent computational studies $^{\mathbf{4 6}}$ suggest a reinterpretation of the difference signal contribution previously interpreted as arising from a density change as discussed in the ESI. $\uparrow$ Critical to the current study, the extracted time dependent $\mathrm{Fe}-\mathrm{N}$ bond length does not depend upon the inclusion, or exclusion, of the density term.

As $\Delta S_{d(\mathrm{Fe}-\mathrm{N})}(Q, t)$ and $\Delta S_{\text {cage }}(Q)$ depend linearly on the excitation fraction $(\alpha(t))$ the final expression used to model the difference scattering signal becomes,

$$
\begin{aligned}
\Delta S(Q, t)=\alpha(t)\left(\Delta S_{d(\mathrm{Fe}-\mathrm{N})}\right. & \left.(Q, t)+\beta(t) \Delta S_{\mathrm{cage}}(Q)\right) \\
& +\Delta T(t) \Delta S_{T}(Q)+\Delta \rho(t) \Delta S_{\rho}(Q)
\end{aligned}
$$

We calculate the solute contribution to the XDS signal, $\Delta S_{d(\mathrm{Fe}-}$ $\mathrm{N})(Q, t)$, from the DFT-optimized molecular structures of $\left[\mathrm{Fe}(\mathrm{bpy})_{3}\right]^{2+}$ in the lowest energy singlet electronic state by linearly interpolating the $\mathrm{Fe}-\mathrm{N}$ bond distances in steps of $0.001 \AA$ by moving the bipyridine ligands with respect to the Fe center such that all $\mathrm{Fe}-\mathrm{N}$ distances and $\mathrm{N}-\mathrm{Fe}-\mathrm{N}$ bond angles remain equal.
We do not use optimized structures for each symmetric $\mathrm{Fe}-\mathrm{N}$ bond length because not all molecular coordinates will remain in equilibrium with the underdamped symmetric $\mathrm{Fe}-\mathrm{N}$ bond oscillations and the subtle changes in ligand bonding that occur between the low- and high-spin states do not measurably change the intramolecular structure factor. The solute difference scattering signal is calculated for each structural configuration (each Fe-N bond length) using the Debye equation, ${ }^{25}$ followed by subtraction of the scattering signal calculated for the ground state. The cage signal $\Delta S_{\text {cage }}(Q, t)$, is identical to the one used by Haldrup et $a .^{19}$ and calculated from the solute-solvent radial distribution function (RDF) generated from equilibrated MD trajectories of the GS and ${ }^{5} \mathrm{MC}$ states in aqueous solution. ${ }^{47}$ This model of the cage signal does not account for the solvent reorganization that will occur in response to MLCT excitation. This may explain, in part, the discrepancies between the model and the XDS experiment during the first 150 fs. We treat the time dependent transition in the solvation cage as the time dependent scaling, $\beta(t)$, of the difference signal created by the subtraction of the solvation cage for the low- and high-spin equilibrated cage signals. This conforms to the widely observed trend in time resolved XDS measurements that fractional changes in intermolecular distances of up to $10 \%$ appear as changes in a $Q$ independent amplitude. ${ }^{48}$ The density and temperature components $\Delta S_{\rho}(Q)$ and $\Delta S_{T}(Q)$, are taken from reference measurements (https://sites.google.com/site/trwaxs/home/TRWAXSdata). ${ }^{49}$ As such, the difference scattering signal from each time delay is fit with the Fe-N bond length distance $\left(d_{\mathrm{Fe}-\mathrm{N}}\right)$, the cage response amplitude $\beta(t), \Delta T(t)$ and $\Delta \rho(t)$ as free parameters, with $\alpha(t)$ determined from the XES analysis described above.

The difference scattering signal and corresponding fit is shown for selected time delays in Fig. 4A. The four difference scattering components used to fit the data are shown in Fig. 4BE. Fig. $4 \mathrm{~F}$ shows the difference scattering signal at 150 fs (gray circles), the full fit of the model (cyan curve) and the contribution from each component of the fit (black, magenta, red and blue). The time dependent $\mathrm{Fe}-\mathrm{N}$ bond length dynamics (mapped by the Fe-N distance) are shown in Fig. 5 and the time evolution of all parameters are shown in the ESI. $\uparrow$ The time dependent Fe$\mathrm{N}$ bond length dynamics display clear oscillations for $t<1 \mathrm{ps,}$ which are fitted in the ESI. $\uparrow$ From the fit, we retrieve a period for the Fe-N oscillations of $235 \pm 14$ fs matching the 236 fs $\mathrm{Fe}-\mathrm{N}$ stretch oscillation observed in both TA and XANES experiments, ${ }^{13,31}$ a dephasing lifetime of $340 \pm 80$ fs matching the XANES experiments, ${ }^{13}$ and we retrieve a lifetime for the vibrational cooling of $1.4 \pm 0.3 \mathrm{ps}$, similar to the $1.6 \pm 0.1 \mathrm{ps}$ lifetime of vibrational cooling retrieved from the XANES experiments. ${ }^{13}$ Additionally, the time dependent bond length extracted from the XDS measurement has an asymptotic change in the $\mathrm{Fe}-\mathrm{N}$ bond length of $0.2 \AA$, as shown in ESI Fig. S2, $\dagger$ equal to that seen previously with ultrafast XANES measurements. ${ }^{13,50}$

\section{Excited state relaxation dynamics}

The excited state populations and average $\mathrm{Fe}-\mathrm{N}$ bond length dynamics of $\left[\mathrm{Fe}(\mathrm{bpy})_{3}\right]^{2+}$ extracted from the combined XES and XDS experiment are summarized in Fig. 5. 
(A)

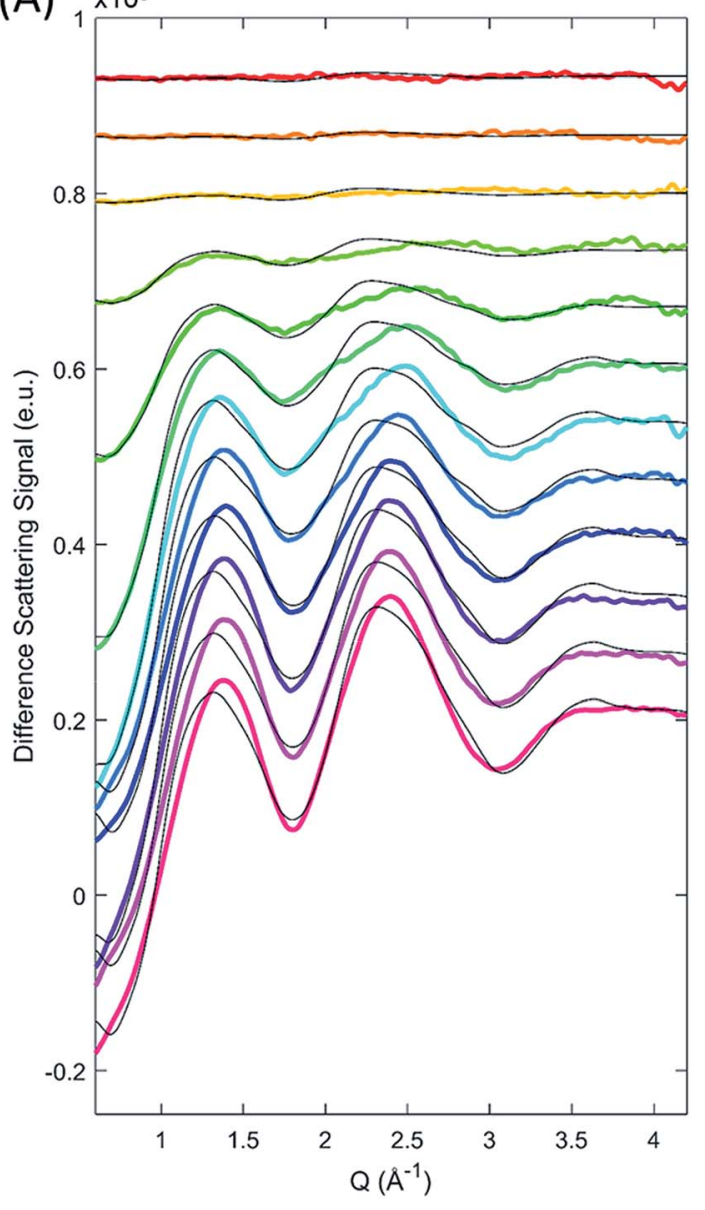
fit and fit components for the 150 fs time-delay data (F).
(B)
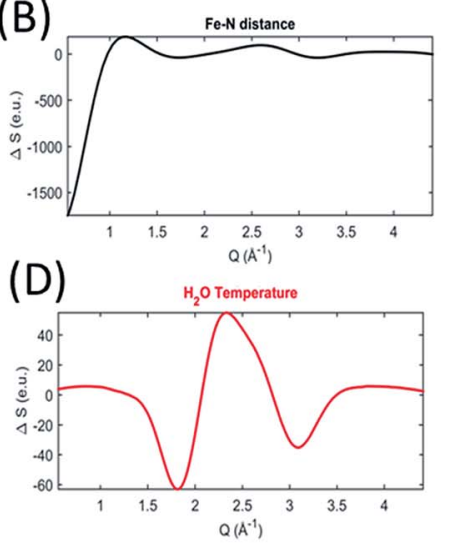

(E)
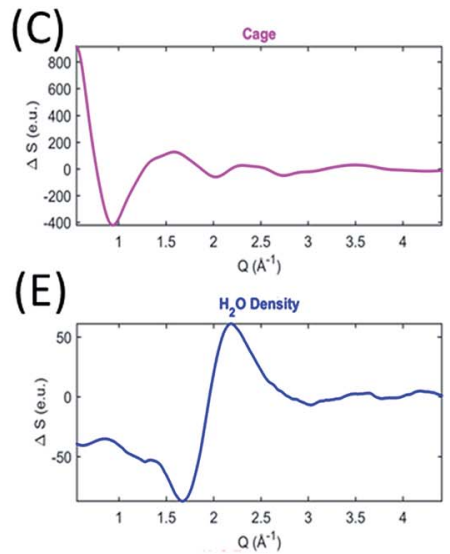

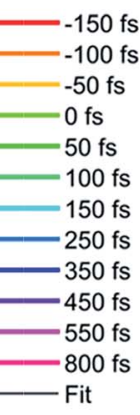

(F)

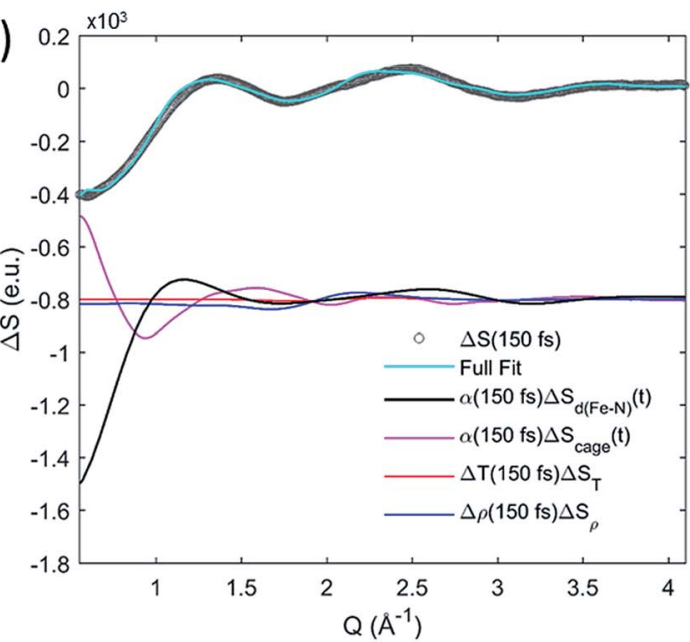

Fig. 4 Extracting the excited state structural dynamics from XDS measurements. XDS data (colored curves) and fit (grey curves) at selected time delays (A). Examples of the difference scattering components used to describe the XDS signal, the solute signal (B) is shown for a $0.2 \AA$ bondlength expansion at an excitation fraction of 1, the cage term $(C)$ is shown for the solvation change between ground state and quintet excited state for an excitation fraction of 1 , and the solvent signals are shown for a $1 \mathrm{~kg} \mathrm{~m}^{-3}$ density $(D)$ and $1 \mathrm{~K}$ temperature (E) increase respectively. Data,

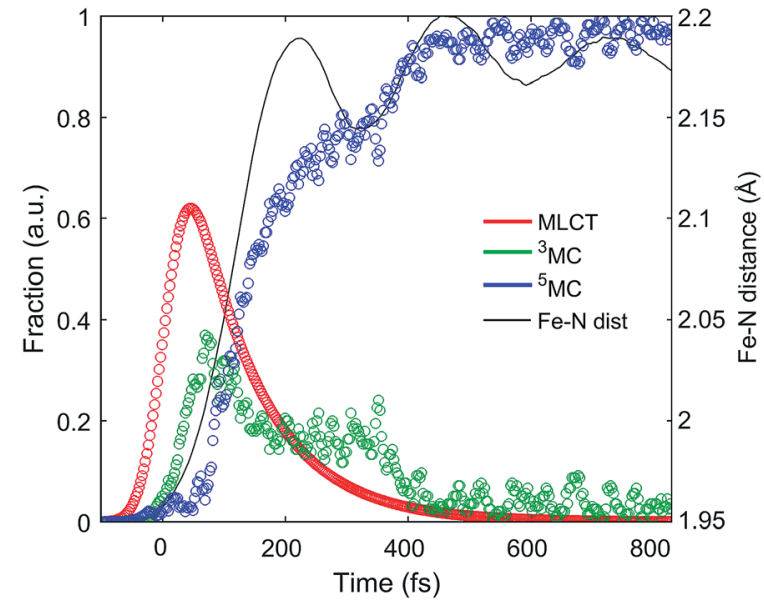

Fig. 5 Excited state electronic dynamics extracted from the XES and dynamics of the Fe-N bond length distance extracted from XDS.
The improvement in XES data quality and time resolution compared to our previous measurements demonstrate that the ${ }^{3} \mathrm{MC} \rightarrow{ }^{5} \mathrm{MC}$ transition is governed by non-exponential dynamics. This is readily visible from the plateau in the ${ }^{3} \mathrm{MC}$ population at time delays between $200 \mathrm{fs}$ and $350 \mathrm{fs}$, concurrent with a shoulder in the ${ }^{5} \mathrm{MC}$ population, which can be seen directly from the recorded XES difference data (Fig. S5 $†$ ). Note the small population of the ${ }^{3} \mathrm{MC}$ state beyond 400 fs does not exceed the uncertainty in the analysis and likely reflects the limitations of the model spectra used in the analysis. The XES clearly shows a recurrence in the ${ }^{3} \mathrm{MC}$ population coincident with the vibrational wave packet on the ${ }^{5} \mathrm{MC}$ PES, tracked by the XDS, arriving at the inner turning point at roughly $350 \mathrm{fs}$. This demonstrates that the evolution of the ${ }^{3} \mathrm{MC}$ state and the ${ }^{5} \mathrm{MC}$ state populations formed from the MLCT relaxation depend directly on the underdamped oscillation along the $\mathrm{Fe}-\mathrm{N}$ symmetric stretching coordinate. This leads to both forward and back transfer of population between the ${ }^{3} \mathrm{MC}$ and ${ }^{5} \mathrm{MC}$ states occurring over a narrow range of $\mathrm{Fe}-\mathrm{N}$ bond lengths. $\mathrm{A}$ 
model description of such excited state dynamics, with a strong interplay between excited state electronic and structural dynamics, can be achieved by describing the dynamics directly on one-dimensional potential energy curves for the MLCT, ${ }^{3} \mathrm{MC}$, and ${ }^{5} \mathrm{MC}$ electronic excited states (see Fig. 6C).

Within this one-dimensional $\mathrm{Fe}-\mathrm{N}$ symmetric bond length description of motion on multiple PES, the molecules transitioning into the ${ }^{3} \mathrm{MC}$ from the MLCT state see a very steep gradient along the $\mathrm{Fe}-\mathrm{N}$ bond length coordinate. The gradient generates a ballistic bond expansion bringing the system towards the intersection between the ${ }^{3} \mathrm{MC}$ and ${ }^{5} \mathrm{MC}$ excited states where transitions to the ${ }^{5} \mathrm{MC}$ state occur with a very high probability. The simplest way to implement a model with such a structure-dependent transition probability is to describe the ${ }^{3} \mathrm{MC} \rightarrow{ }^{5} \mathrm{MC}$ transition of each molecule as a unitary probability transition that occurs after a fixed 'wait time' following the initial MLCT $\rightarrow{ }^{3} \mathrm{MC}$ transition. This would correspond to each molecular trajectory undergoing ${ }^{3} \mathrm{MC} \rightarrow{ }^{5} \mathrm{MC}$ transition with unitary probability near a well-defined $\mathrm{Fe}-\mathrm{N}$ symmetric bond length on the ${ }^{3} \mathrm{MC}$ potential energy surface as indicated by the black arrow in Fig. 6C. Fig. 6A and B show the best fits to the initial electronic state kinetics within the first $200 \mathrm{fs}$ with the ${ }^{3} \mathrm{MC} \rightarrow{ }^{5} \mathrm{MC}$ transition being assigned either an exponential decay (Fig. 6A) or a wait time following the MLCT $\rightarrow{ }^{3} \mathrm{MC}$ transition (Fig. 6B). For the exponential dynamics, we obtain the best fit with a $72 \mathrm{fs}^{3} \mathrm{MC}$ lifetime, and for the ballistic dynamics we obtain the best fit for a ${ }^{3} \mathrm{MC}$ residence time of $58 \mathrm{fs}$. As seen from Fig. $6 \mathrm{~A}$ and $\mathrm{B}$, the model describing the transition by a wait time better matches both the amplitude of the ${ }^{3} \mathrm{MC}$ maximum, the onset of the ${ }^{5} \mathrm{MC}$ population growth, and the shape of the ${ }^{3} \mathrm{MC}$ decay. Including a direct transition between the MLCT and ${ }^{5} \mathrm{MC}$ states in the model do not improve the fit, indicating that nearly all of the excited state ensemble passes through the ${ }^{3} \mathrm{MC}$ state on the way to the ${ }^{5} \mathrm{MC}$ excited state.

A 58 fs residence time on the ${ }^{3} \mathrm{MC}$ potential energy surface is slightly shorter than a quarter period of the coherent oscillations on the ${ }^{5} \mathrm{MC}$ PES. The period of oscillations on the ${ }^{3} \mathrm{MC}$ surface are expected to be in between the 230 fs and 265 fs identified for the breathing modes of the GS and ${ }^{5} \mathrm{MC}$ states respectively. ${ }^{13,35}$ Therefore, a wait time of $58 \mathrm{fs}$ indicates that the excited state ${ }^{3} \mathrm{MC} \rightarrow{ }^{5} \mathrm{MC}$ transition occurs over a narrow range of Fe-N symmetric stretch bond lengths near the minimum of the ${ }^{3} \mathrm{MC}$ potential.

This analysis also resolves the apparent contradiction between previous studies ${ }^{13,15,31}$ of the photo-induced spin crossover dynamics of $\left[\mathrm{Fe}(\mathrm{bpy})_{3}\right]^{2+}$. XES robustly observes the presence of the ${ }^{3} \mathrm{MC}$ transient, but does not characterize the $\mathrm{Fe}-$ $\mathrm{N}$ bond length expansion. By simultaneously measuring the spin state dynamics with XES and $\mathrm{Fe}-\mathrm{N}$ bond length dynamics with XDS, we have the necessary electronic state and nuclear dynamics constraints needed to confirm the presence of a ${ }^{3} \mathrm{MC}$ transient and the ballistic expansion of the $\mathrm{Fe}-\mathrm{N}$ symmetric bond length seen with XANES and optical transient absorption measurements. The factor of two difference between the MLCT lifetime measured in this study compared to that of Auböck and Chergui warrants comment. ${ }^{31}$ Auböck and Chergui use the $50 \mathrm{fs}$ phase shift in the $\mathrm{Fe}-\mathrm{N}$ symmetric stretching oscillation to indicate the time scale for MLCT excited state decay. In the present study a similar phase shift is observed in the XDS, but the ultrafast XES provides a clear signature for the MLCT excited state and indicates that the phase of the vibration provides a less robust method for determining the MLCT decay time.

\section{Excited state modeling}

The success of the coarse grained model description of photoinduced spin crossover dynamics shown in Fig. 6B indicates that the experimental correlation between electronic state and nuclear structural dynamics provides direct access to a onedimensional projection of the excited state relaxation dynamics on the ${ }^{3} \mathrm{MC}$ and ${ }^{5} \mathrm{MC}$ potential energy surfaces onto the $\mathrm{Fe}-\mathrm{N}$ symmetric stretching vibrational coordinate. In order to account for ${ }^{5} \mathrm{MC} \rightarrow{ }^{3} \mathrm{MC}$ back transfer, we require a model for the excited state cascade that simultaneously describes both electronic and structural dynamics. In the following section, we will describe the results obtained by directly modeling the dynamics of the excited state relaxation on the calculated
(A)

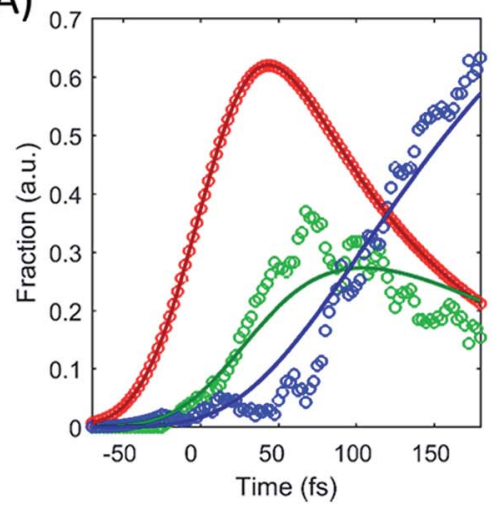

(B)

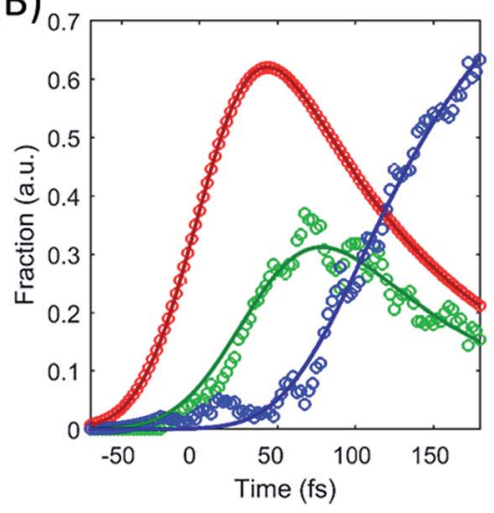

(C)

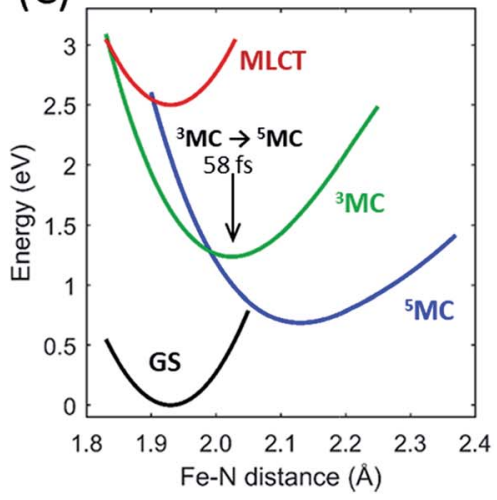

Fig. 6 Fitting the excited state electronic kinetics with exponential or ballistic transport through the ${ }^{3} \mathrm{MC}$ state. The transit of the excited state cascade through the ${ }^{3} \mathrm{MC}$ state has been fitted with (A) an exponential lifetime of the ${ }^{3} \mathrm{MC}$ state, and (B) a wait time for the ${ }^{3} \mathrm{MC} \rightarrow{ }^{5} \mathrm{MC}$ transition (following the MLCT $\rightarrow{ }^{3} \mathrm{MC}$ transition). The model used in (B) describes a situation where the ${ }^{3} \mathrm{MC} \rightarrow{ }^{5} \mathrm{MC}$ transition happens in a very narrow range on the optimized PES used in the model and illustrated by the black arrow in (C), with the best fit returning a 58 fs wait time. 
potential energy surfaces of the system and quantitatively optimizing this model description against the recorded excited state dynamics.

Our model framework for the excited state relaxation builds on the model established to describe ultrafast XANES $^{13}$ measurements of $\left[\mathrm{Fe}(\mathrm{bpy})_{3}\right]^{2+}$ and the calculated PES of Sousa et al. ${ }^{35} \mathrm{~A}$ detailed description of the model can be found in ESI Note $8 . \dagger$ The model describes both the electronic transitions extracted from the fit of the XES data, and the Fe-N bond-length distance dynamics extracted from the XDS data. The model returns the simulated electronic and structural dynamics of an ensemble of $10^{5}$ molecules each having a well-defined $\mathrm{Fe}-\mathrm{N}$ distance and electronic state for each time delay. The $\mathrm{Fe}-\mathrm{N}$ distance of each molecule is propagated classically on the excited state potential energy surface on which they reside (experiencing a force given by the slope of the PES). The XANES measurements of Lemke et al. ${ }^{13}$ provide a handle on the width of $\mathrm{Fe}-\mathrm{N}$ bond length distribution, a parameter that cannot be readily extracted from XDS data. We have therefore used the structural distribution of the MLCT state, as well as the dephasing, dampening, and thermostat terms presented by Lemke et al. to describe the solvent collisions and intramolecular vibrational redistribution processes. The simulation is initialized at time-zero, with all excited state systems being moved to the MLCT surface. From the MLCT surface, each system has a time-independent transition probability to the ${ }^{3} \mathrm{MC}$ surface, such that the MLCT ensemble decays with the 110 fs exponential lifetime identified in the XES experiments. The systems are then propagated classically on the ${ }^{3} \mathrm{MC}$ potential energy surface, until they reach a $\mathrm{Fe}-\mathrm{N}$ distance defining the intersection point between the ${ }^{3} \mathrm{MC}$ and ${ }^{5} \mathrm{MC}$ surfaces. At the point of intersection, the system trajectories are shifted to the ${ }^{5} \mathrm{MC}$ surface with a given transition probability, and are then propagated on the resultant PES. After reaching the outer turning point of the ${ }^{5} \mathrm{MC}$ potential, the trajectories can revisit the ${ }^{5} \mathrm{MC} /{ }^{3} \mathrm{MC}$ intersection at which they have a probability of transitioning back to the ${ }^{3} \mathrm{MC}$ potential. The simulation explicitly quantifies the excited electronic state and the $\mathrm{Fe}-\mathrm{N}$ bond length of each molecule and reproduces the experimental observables from an ensemble average of simulated trajectories. The model description provided by the simulation can therefore be quantitatively compared to the experimental results and incorporated into a $\chi^{2}$ analysis that allow us to optimize the shape and position of the potential energy surfaces directly against the data.

The model has nine parameters. Three parameters, $t_{0}, \sigma_{\mathrm{IRF}}$, and $\tau_{\mathrm{MLCT}}$, are determined by alternative analyses and fixed in the simulation. We use the $\mathrm{Fe}-\mathrm{N}$ bond-length distribution in the MLCT state and vibrational cooling dynamics extracted from the XANES analysis presented by Lemke $e t$ al. ${ }^{13}$ due to the higher sensitivity of XANES, than XDS, to the Fe-N bond length distribution. We explicitly extract the final four parameters directly from the simulation: the location of the initial ${ }^{3} \mathrm{MC} \rightarrow$ ${ }^{5} \mathrm{MC}$ intersection, the location of the back transfer ${ }^{3} \mathrm{MC} \rightarrow{ }^{5} \mathrm{MC}$ intersection, the transition probability between the ${ }^{3} \mathrm{MC}$ and ${ }^{5} \mathrm{MC}$ excited states at these intersections, and a scaling parameter for the shape of the potential energy surfaces.
Two of the optimized parameters, the transition probability and the curvature scaling of the Fe- $\mathrm{N}$ stretching potential, can be optimized independently from the remaining parameters. The best fits are achieved with a transition probability of 1 , with the quality of the fit becoming significantly worse for transition probabilities below 0.8. The curvature of the Fe-N symmetric stretching potential energy surfaces calculated by Sousa et al. ${ }^{35}$ have to be reduced by a factor of $0.89 \pm 0.05$ to match the observed oscillation frequency in the ${ }^{5} \mathrm{MC}$ electronic state. The best description of the data is provided when the initial ${ }^{3} \mathrm{MC} \rightarrow$ ${ }^{5} \mathrm{MC}$ intersection occurs near the ${ }^{3} \mathrm{MC}$ potential energy minimum $2.05 \pm 0.01 \AA$, whereas the subsequent ${ }^{5} \mathrm{MC} \rightarrow{ }^{3} \mathrm{MC}$ back transfer occurs very close to the calculated intersection for isotropic bond length changes at $1.98 \pm 0.02 \AA$. The simulated dynamics for this model, which provides the best description of the experimental dynamics, is compared to the experimental dynamics in Fig. 7A. Fig. 6C shows the experimentally optimized potential energy surfaces and the points of intersection between the ${ }^{3} \mathrm{MC}$ and ${ }^{5} \mathrm{MC}$ states projected onto the $\mathrm{Fe}-\mathrm{N}$ symmetric bond length. The resulting $\mathrm{Fe}-\mathrm{N}$ bond length distribution can be seen in Fig. 7B. With this parametrization, the mean residence time for the initial passage through the ${ }^{3} \mathrm{MC}$ state is $55 \mathrm{fs}$, matching well with the 58 fs derived with the waiting time model fit to the XES data.

The results of the model in Fig. 7B show that both the electronic and the structural dynamics of the system can be modeled by optimization of four free parameters, with two of these being uncorrelated with the others. Inspection of the best fit and the experimental populations shows that the model shows faster population transfer from the ${ }^{3} \mathrm{MC}$ to the ${ }^{5} \mathrm{MC}$ state, though not significantly outside the uncertainty in the measurement. This may indicate that the transitions between ${ }^{3} \mathrm{MC}$ and ${ }^{5} \mathrm{MC}$ occur over a narrow range of $\mathrm{Fe}-\mathrm{N}$ bond lengths, rather than a single bond length. This would be expected, but the experimental measurement does not warrant a more complex model than the one utilized. Moving beyond the level of detail we present here would require robust theoretical support.

The different location for the intersection between the ${ }^{3} \mathrm{MC}$ and ${ }^{5} \mathrm{MC}$ states for the forward $\left({ }^{3} \mathrm{MC} \rightarrow{ }^{5} \mathrm{MC}\right)$ and back $\left({ }^{5} \mathrm{MC} \rightarrow\right.$ ${ }^{3} \mathrm{MC}$ ) reactions represents the most significant finding of the analysis of the experimental data. This could not occur if only one vibrational degree of freedom and one ${ }^{3} \mathrm{MC}$ state participated in the transition between the ${ }^{3} \mathrm{MC}$ and ${ }^{5} \mathrm{MC}$ excited states. As shown in Fig. 1B, both a ${ }^{3} \mathrm{~T}_{1}$ and ${ }^{3} \mathrm{~T}_{2}$ electronic state could participate in the photo-induced spin crossover and these distinct triplet states intersect with the ${ }^{5} \mathrm{~T}_{2}$ state at different $\mathrm{Fe}-$ $\mathrm{N}$ bond lengths. Constraining the dynamics to one dimensional curves shown in Fig. 1B, a circumstance where the back transfer occurred for a shorter $\mathrm{Fe}-\mathrm{N}$ bond length than the forward transfer cannot be easily rationalized. The inability of onedimensional surfaces to describe the relevant dynamics provides a more likely explanation, highlighting the broader significance of understanding multidimensional potential energy surface properties for understanding ultrafast dynamics processes..$^{51}$ Most critically, the ${ }^{3} \mathrm{MC}$ state will have a single electron in a 3d-dominated $e_{g}$ orbital making the molecule 
(A)

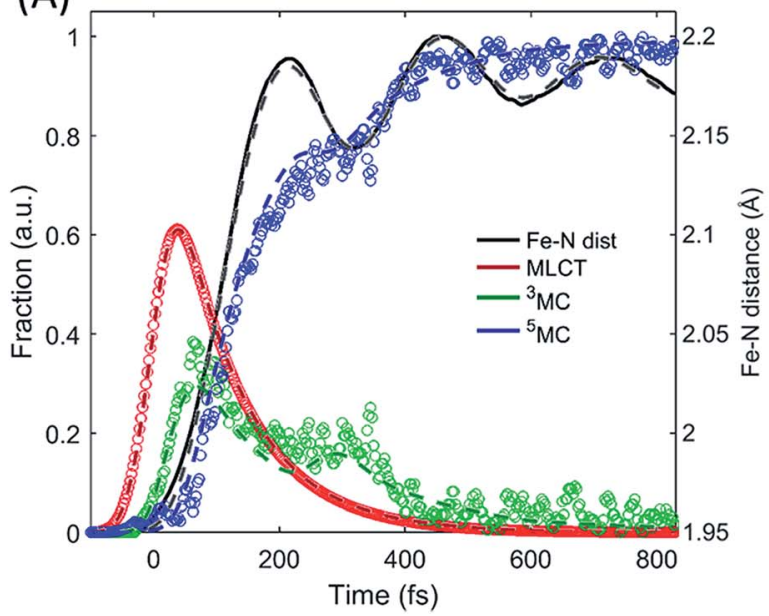

(B)

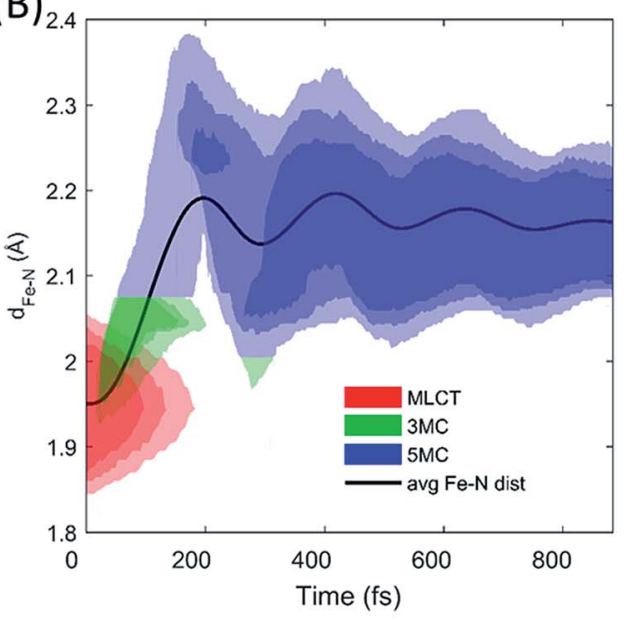

Fig. 7 Simulating the experimentally determined excited state dynamics. Using the potential energy surfaces in Fig. $6 \mathrm{C}$ and the modelling described in the text, an accurate fit (dashed lines) of the excited state population dynamics extracted from the XES measurement (circles) and $\mathrm{Fe}-\mathrm{N}$ ensemble average bond length (line) has been achieved (A). The distribution of Fe-N distances and the electronic state occupied by the simulated excited state ensemble are shown in (B).

pseudo-Jahn-Teller active. When molecules propagate on the ${ }^{3} \mathrm{MC}$ PES, they will experience a tetragonal distortion gradient in addition to the Fe-N bond expansion gradient. This should be contrasted with the ${ }^{5} \mathrm{MC}$ state which has a near octahedral coordination sphere with no tetragonal distortion. Consequently, the initial ${ }^{3} \mathrm{MC} \rightarrow{ }^{5} \mathrm{MC}$ transition should occur along a trajectory involving $\mathrm{Fe}-\mathrm{N}$ bond expansion and tetragonal $\mathrm{Fe}-\mathrm{N}$ bond distortion, while the ${ }^{5} \mathrm{MC} \rightarrow{ }^{3} \mathrm{MC}$ back transfer will involve trajectories dominated by oscillations in the $\mathrm{Fe}-\mathrm{N}$ symmetric bond length. A schematic representation of these dynamics and how they could lead to distinct points of intersection for the forward and back reactions can be found in Fig. 8. Ambiguity remains because we observe the projection of trajectories on the multi-dimension potential energy surfaces onto the symmetric Fe-N stretching coordinate; we do not directly resolve any other intramolecular structural degrees of freedom.

\section{Closing remarks}

We have shown that robust analysis of simultaneously recorded X-ray diffuse scattering and X-ray emission spectroscopy enables the electronic and nuclear trajectory of electronic excited states on multiple potential energy surfaces to be extracted from measurement. The method has been used to provide a clear mechanistic picture for light-induced spin crossover in $\left[\mathrm{Fe}(\mathrm{bpy})_{3}\right]^{2+}$. We conclude that the dominant trajectory involves transit through a ${ }^{3} \mathrm{MC}$ state, and that the light-induced spin crossover occurs as a cascade of singleelectron transitions strongly coupled to large-scale structural dynamics along the metal-ligand stretch reaction coordinate. Transitions between the MC states occur through points of intersection with near unity transition probability, clearly visible as non-exponential dynamics exemplified by the observation that a subset of the excited states revisit the ${ }^{3} \mathrm{MC}$ state at the first inner turning point of the activated metal-ligand stretch vibration. Using a model to simultaneously fit both electronic state and nuclear structural dynamics provides quantification of the loci of intersections between the metalcentered excited state potential energy surfaces. The quantification reveals a small but significant difference in the position of intersections along the metal-ligand stretch reaction coordinate for the forward ${ }^{3} \mathrm{MC} \rightarrow{ }^{5} \mathrm{MC}$ reaction and the back ${ }^{5} \mathrm{MC}$ $\rightarrow{ }^{3} \mathrm{MC}$ reaction. This may result from the expected tetragonal distortion of the $\mathrm{Fe}-\mathrm{N}$ bonds on the ${ }^{3} \mathrm{MC}$ potential, illustrating

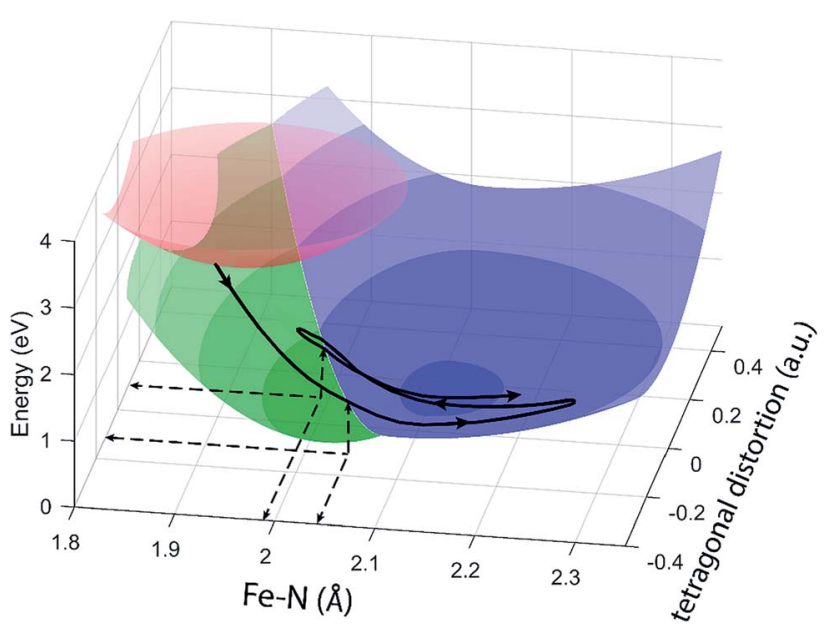

Fig. 8 Schematic of the excited state trajectory of $\left[\mathrm{Fe}(\mathrm{bpy})_{3}\right]^{2+}$ through its excited state potential energy landscape. Colored surfaces are the potential energy surfaces of the MLCT (red), ${ }^{3} \mathrm{MC}$ (green), and ${ }^{5} \mathrm{MC}$ (blue) drawn around the calculated minimum positions seen from two different angles, note than the ${ }^{3} \mathrm{MC}$ and ${ }^{5} \mathrm{MC}$ potential energy surfaces are only drawn where they are the lowest lying surface. The black line represents the initial part of a trajectory through the potential energy landscape for an $\left[\mathrm{Fe}(\mathrm{bpy})_{3}\right]^{2+}$ system undergoing back-transfer onto the ${ }^{3} \mathrm{MC}$ potential energy surface. 
that intersystem crossing and internal conversion happens along a seam between the potential energy surfaces spanned by the $\mathrm{Fe}-\mathrm{N}$ stretch coordinate, and the $\mathrm{Fe}-\mathrm{N}$ tetragonal distortion coordinate.

The intersections and seams between the excited state potential energy surfaces govern electronic excited state reaction mechanisms in analogy with the transition state for electronic ground state reaction mechanisms. Robust parametrization of such intersections and seams has long been a key objective for ultrafast studies of chemical dynamics and these measurements demonstrate the clear value of joint ultrafast X-ray spectroscopy and diffuse scattering measurements for characterizing the complex reaction dynamics of electronically excited $3 \mathrm{~d}$ transition metal complexes in solution, particularly when these dynamics involve changes in the charge and spin state of the metal-center strongly coupled to changes in the metal-ligand bond lengths, ligand number, and symmetry. These measurements may also assist the development of quantum dynamics simulations for 3d transition metal systems, which in turn will be critical to developing a deeper understanding of the molecular properties that control the excited state dynamics of these complexes.

\section{Conflicts of interest}

There are no conflicts to declare.

\section{Acknowledgements}

Use of the Linac Coherent Light Source (LCLS), SLAC National Accelerator Laboratory, is supported by the U.S. Department of Energy, Office of Science, Office of Basic Energy Sciences under Contract No. DE-AC02-76SF00515. Work by KK, MER, and KJG was supported by the U.S. Department of Energy, Office of Science, Basic Energy Sciences, Chemical Sciences, Geosciences, and Biosciences Division. KL acknowledges a Melvin and Joan Lane Stanford Graduate Fellowship. KSK, KH, MMN, MGL, PV, EB, FBH, MC gratefully acknowledge DANSCATT support for the beamtime efforts. TCBH, EB, MGL, MIP, KBM, and MMN gratefully acknowledge support by the Danish Council for Independent Research under grant no. DFF-400200272B. MIP, MMN, and KBM acknowledge support by the Danish Council for Independent Research under grant no. DFF-8021-00347B. KSK gratefully acknowledge the support of the Carlsberg Foundation and the Danish Council for Independent Research. MIP, DSS, EB, and GV acknowledge support from the 'Lendület' (Momentum) Program of the Hungarian Academy of Sciences (LP2013-59), the Government of Hungary and the European Regional Development Fund under grant No. VEKOP-2.3.2-16-2017-00015, the European Research Council via contract ERC-StG-259709 (X-cited!), the Hungarian Scientific Research Fund (OTKA) under contract K 109257, and the National Research, Development and Innovation Fund (NKFIH FK 124460). ZN acknowledges support from the Bolyai Fellowship of the Hungarian Academy of Sciences. SC acknowledges the ELI-ALPS project (GINOP-2.3.6-15-2015-00001) which is supported by the European Union and co-financed by the
European Regional Development Fund. VS, JU, and PP acknowledge support from the Knut and Alice Wallenberg Foundation (KAW). SK acknowledges the support from Knut \& Alice Wallenberg foundation (KAW 2014.0370). AOD acknowledges support by the Icelandic Research Fund (Grant\# 196279051).

\section{References}

1 G. Vanko, P. Glatzel, V. T. Pham, R. Abela, D. Grolimund, C. N. Borca, S. L. Johnson, C. J. Milne and C. Bressler, Angew. Chem., Int. Ed., 2010, 49, 5910-5912.

2 K. H. Kim, J. G. Kim, S. Nozawa, T. Sato, K. Y. Oang, T. Kim, H. Ki, J. Jo, S. Park, C. Song, T. Sato, K. Ogawa, T. Togashi, K. Tono, M. Yabashi, T. Ishikawa, J. Kim, R. Ryoo, J. Kim, H. Ihee and S. Adachi, Nature, 2015, 518, 385-389.

3 H. Ihee, M. Wulff, J. Kim and S.-i. Adachi, Int. Rev. Phys. Chem., 2010, 29, 453-520.

4 J. E. Monat and J. K. McCusker, J. Am. Chem. Soc., 2000, 122, 4092-4097.

5 T. J. Martinez, Nature, 2010, 467, 412-413.

6 W. Domcke and D. R. Yarkony, in Annual Review of Physical Chemistry, ed. M. A. Johnson and T. J. Martinez, 2012, vol. 63, pp. 325-352.

7 A. H. Zewail, J. Phys. Chem. A, 2000, 104, 5660-5694.

8 A. H. Zewail, Science, 1988, 242, 1645-1653.

9 D. R. Yarkony, Rev. Mod. Phys., 1996, 68, 985-1013.

10 T. S. Rose, M. J. Rosker and A. H. Zewail, J. Chem. Phys., 1989, 91, 7415-7436.

11 N. F. Scherer, D. M. Jonas and G. R. Fleming, J. Chem. Phys., 1993, 99, 153-168.

12 M. Chergui and E. Collet, Chem. Rev., 2017, 117, 1102511065.

13 H. Lemke, K. S. Kjær, R. W. Hartsock, T. B. van Driel, M. Chollet, J. M. Glownia, S. H. Song, D. L. Zhu, E. Pace, S. F. Matar, M. M. Nielsen, M. Benfatto, K. J. Gaffney, E. Collet and M. Cammarata, Nat. Commun., 2017, 8, 15342.

14 H. T. Lemke, C. Bressler, L. X. Chen, D. M. Fritz, K. J. Gaffney, A. Galler, W. Gawelda, K. Haldrup, R. W. Hartsock, H. Ihee, J. Kim, K. H. Kim, J. H. Lee, M. M. Nielsen, A. B. Stickrath, W. K. Zhang, D. L. Zhu and M. Cammarata, J. Phys. Chem. A, 2013, 117, 735-740.

15 W. Zhang, R. Alonso-Mori, U. Bergmann, C. Bressler, M. Chollet, A. Galler, W. Gawelda, R. G. Hadt, R. W. Hartsock, T. Kroll, K. S. Kjaer, K. Kubicek, H. T. Lemke, H. W. Liang, D. A. Meyer, M. M. Nielsen, C. Purser, J. S. Robinson, E. I. Solomon, Z. Sun, D. Sokaras, T. B. van Driel, G. Vanko, T.-C. Weng, D. Zhu and K. J. Gaffney, Nature, 2014, 509, 345-348.

16 E. Biasin, T. B. van Driel, K. S. Kjaer, A. O. Dohn, M. Christensen, T. Harlang, P. Chabera, Y. Z. Liu, J. Uhlig, M. Papai, Z. Nemeth, R. Hartsock, W. Liang, J. X. Zhang, R. Alonso-Mori, M. Chollet, J. M. Glownia, S. Nelson, D. Sokaras, T. A. Assefa, A. Britz, A. Galler, W. Gawelda, C. Bressler, K. J. Gaffney, H. T. Lemke, K. B. Moller, M. M. Nielsen, V. Sundstrom, G. Vanko, K. Warnmark, 
S. E. Canton and K. Haldrup, Phys. Rev. Lett., 2016, 117, 013002.

17 T. B. van Driel, K. S. Kjær, R. W. Hartsock, A. O. Dohn, T. Harlang, M. Chollet, M. Christensen, W. Gawelda, N. E. Henriksen, J. G. Kim, K. Haldrup, K. H. Kim, H. Ihee, J. Kim, H. Lemke, Z. Sun, V. Sundström, W. Zhang, D. Zhu, K. B. Møller, M. M. Nielsen and K. J. Gaffney, Nat. Commun., 2016, 7, 13678.

18 K. S. Kjaer, Z. Wenkai, R. Alonso-Mori, U. Bergmann, M. Chollet, R. G. Hadt, R. W. Hartsock, T. Harlang, T. Kroll, K. Kubicek, H. T. Lemke, H. W. Liang, L. Yizhu, M. M. Nielsen, J. S. Robinson, E. I. Solomon, D. Sokaras, T. B. van Driel, W. Tsu-Chien, Z. Diling, P. Persson, K. Warnmark, V. Sundstrom and K. J. Gaffney, Struct. Dyn., 2017, 4, 044030.

19 K. Haldrup, W. Gawelda, R. Abela, R. Alonso-Mori, U. Bergmann, A. Bordage, M. Cammarata, S. E. Canton, A. O. Dohn, T. B. van Driel, D. M. Fritz, A. Galler, P. Glatzel, T. Harlang, K. S. Kjaer, H. T. Lemke, K. B. Moller, Z. Nemeth, M. Papai, N. Sas, J. Uhlig, D. L. Zhu, G. Vanko, V. Sundstrom, M. M. Nielsen and C. Bressler, J. Phys. Chem. B, 2016, 120, 1158-1168.

20 S. E. Canton, K. S. Kjær, G. Vankó, T. B. van Driel, S.-i. Adachi, A. Bordage, C. Bressler, P. Chabera, M. Christensen, A. O. Dohn, A. Galler, W. Gawelda, D. Gosztola, K. Haldrup, T. Harlang, Y. Liu, K. B. Møller, Z. Németh, S. Nozawa, M. Pápai, T. Sato, T. Sato, K. Suarez-Alcantara, T. Togashi, K. Tono, J. Uhlig, D. A. Vithanage, K. Wärnmark, M. Yabashi, J. Zhang, V. Sundström and M. M. Nielsen, Nat. Commun., 2015, 6, 6359.

21 M. Levantino, G. Schiro, H. T. Lemke, G. Cottone, J. M. Glownia, D. L. Zhu, M. Chollet, H. Ihee, A. Cupane and M. Cammarata, Nat. Commun., 2015, 6, 6772.

22 E. Malmerberg, P. H. M. Bovee-Geurts, G. Katona, X. Deupi, D. Arnlund, C. Wickstrand, L. C. Johansson, S. Westenhoff, E. Nazarenko, G. F. X. Schertler, A. Menzel, W. J. de Grip and R. Neutze, Sci. Signaling, 2015, 8, ra26.

23 G. Vanko, T. Neisius, G. Molnar, F. Renz, S. Karpati, A. Shukla and F. M. F. de Groot, J. Phys. Chem. B, 2006, 110, 11647-11653.

24 G. Vanko, A. Bordage, P. Glatzel, E. Gallo, M. Rovezzi, W. Gawelda, A. Galler, C. Bressler, G. Doumy, A. M. March, E. P. Kanter, L. Young, S. H. Southworth, S. E. Canton, J. Uhlig, G. Smolentsev, V. Sundstrom, K. Haldrup, T. B. van Driel, M. M. Nielsen, K. S. Kjaer and H. T. Lemke, J. Electron Spectrosc. Relat. Phenom., 2013, 188, 166-171.

25 K. Haldrup, M. Christensen and M. M. Nielsen, Acta Crystallogr., Sect. A: Found. Crystallogr., 2010, 66, 261-269.

26 D. Leshchev, T. C. B. Harlang, L. A. Fredin, D. Khakhulin, Y. Z. Liu, E. Biasin, M. G. Laursen, G. E. Newby, K. Haldrup, M. M. Nielsen, K. Warnmark, V. Sundstrom, P. Persson, K. S. Kjaer and M. Wulff, Chem. Sci., 2018, 9, 405-414.
27 W. Gawelda, A. Cannizzo, V. T. Pham, F. van Mourik, C. Bressler and M. Chergui, J. Am. Chem. Soc., 2007, 129, 8199-8206.

28 C. Bressler, C. Milne, V. T. Pham, A. ElNahhas, R. M. van der Veen, W. Gawelda, S. Johnson, P. Beaud, D. Grolimund, M. Kaiser, C. N. Borca, G. Ingold, R. Abela and M. Chergui, Science, 2009, 323, 489-492.

29 C. Consani, M. Premont-Schwarz, A. ElNahhas, C. Bressler, F. van Mourik, A. Cannizzo and M. Chergui, Angew. Chem., Int. Ed., 2009, 48, 7184-7187.

30 N. Huse, H. Cho, K. Hong, L. Jamula, F. M. F. de Groot, T. K. Kim, J. K. McCusker and R. W. Schoenlein, J. Phys. Chem. Lett., 2011, 2, 880-884.

31 G. Auböck and M. Chergui, Nat. Chem., 2015, 7, 629-633.

32 C. Sousa, M. Llunell, A. Domingo and C. de Graaf, Phys. Chem. Chem. Phys., 2018, 20, 2351-2355.

33 C. Sousa, A. Domingo and C. de Graaf, Chem.-Eur. J., 2018, 24, 5146-5152.

34 C. Sousa, M. Alias, A. Domingo and C. de Graaf, Chem.-Eur. J., 2019, 25, 1152-1164.

35 C. Sousa, C. de Graaf, A. Rudavskyi, R. Broer, J. Tatchen, M. Etinski and C. M. Marian, Chem.-Eur. J., 2013, 19, 17541-17551.

36 C. de Graaf and C. Sousa, Chem.-Eur. J., 2010, 16, 4550-4556. 37 E. Biasin, T. B. van Driel, G. Levi, M. G. Laursen, A. O. Dohn, A. Moltke, P. Vester, F. B. K. Hansen, K. S. Kjaer, T. Harlang, R. Hartsock, M. Christensen, K. J. Gaffney, N. E. Henriksen, K. B. Moller, K. Haldrup and M. M. Nielsen, J. Synchrotron Radiat., 2018, 25, 306-315.

38 W. Gawelda, Doctor of Philosophy, Ecole Polytechnique Federale de Lausanne, 2006.

39 W. Gawelda, V. T. Pham, R. M. van der Veen, D. Grolimund, R. Abela, M. Chergui and C. Bressler, J. Chem. Phys., 2009, 130, 124520.

40 M. Chollet, R. Alonso-Mori, M. Cammarata, D. Damiani, J. Defever, J. T. Delor, Y. P. Feng, J. M. Glownia, J. B. Langton, S. Nelson, K. Ramsey, A. Robert, M. Sikorski, S. Song, D. Stefanescu, V. Srinivasan, D. L. Zhu, H. T. Lemke and D. M. Fritz, J. Synchrotron Radiat., 2015, 22, 503-507.

41 T. B. van Driel, K. S. Kjaer, E. Biasin, K. Haldrup, H. T. Lemke and M. M. Nielsen, Faraday Discuss., 2015, 177, 443-465.

42 W. Zhang, K. S. Kjaer, R. Alonso-Mori, U. Bergmann, M. Chollet, L. A. Fredin, R. G. Hadt, R. W. Hartsock, T. Harlang, T. Kroll, K. Kubicek, H. T. Lemke, H. W. Liang, Y. Liu, M. M. Nielsen, P. Persson, J. S. Robinson, E. I. Solomon, Z. Sun, D. Sokaras, T. B. van Driel, T.-C. Weng, D. Zhu, K. Warnmark, V. Sundstrom and K. J. Gaffney, Chem. Sci., 2017, 8, 515-523.

43 T. K. Kim, J. H. Lee, M. Wulff, Q. Y. Kong and H. Ihee, ChemPhysChem, 2009, 10, 1958-1980.

44 K. Haldrup, G. Vanko, W. Gawelda, A. Galler, G. Doumy, A. M. March, E. P. Kanter, A. Bordage, A. Dohn, T. B. van Driel, K. S. Kjaer, H. T. Lemke, S. E. Canton, J. Uhlig, V. Sundstrom, L. Young, S. H. Southworth, M. M. Nielsen and C. Bressler, J. Phys. Chem. A, 2012, 116, 9878-9887. 
45 L. M. L. Daku and A. Hauser, J. Phys. Chem. Lett., 2010, 1, 1830-1835.

46 L. M. L. Daku, Phys. Chem. Chem. Phys., 2018, 20, 6236-6253. 47 A. O. Dohn, E. Biasin, K. Haldrup, M. M. Nielsen, N. E. Henriksen and K. B. Moller, J. Phys. B: At., Mol. Opt. Phys., 2015, 48, 244010.

48 K. Haldrup, G. Levi, E. Biasin, P. Vester, M. G. Laursen, F. Beyer, K. S. Kjaer, T. B. van Driel, T. Harlang, A. O. Dohn, R. J. Hartsock, S. Nelson, J. M. Glownia, H. T. Lemke, M. Christensen, K. J. Gaffney, N. E. Henriksen, K. B. Moller and M. M. Nielsen, Phys. Rev. Lett., 2019, 122, 063001.
49 K. S. Kjaer, T. B. van Driel, J. Kehres, K. Haldrup, D. Khakhulin, K. Bechgaard, M. Cammarata, M. Wulff, T. J. Sorensen and M. M. Nielsen, Phys. Chem. Chem. Phys., 2013, 15, 15003-15016.

50 W. Gawelda, V. T. Pham, M. Benfatto, Y. Zaushitsyn, M. Kaiser, D. Grolimund, S. L. Johnson, R. Abela, A. Hauser, C. Bressler and M. Chergui, Phys. Rev. Lett., 2007, 98, 057401.

51 C. S. Ponseca, P. Chabera, J. Uhlig, P. Persson and V. Sundstrom, Chem. Rev., 2017, 117, 10940-11024. 